\title{
Plasma Natriuretic Peptide Concentrations as a Predictor for Successful Catheter Ablation in Patients With Drug-Refractory Atrial Fibrillation
}

\author{
Kenji Kurosaki, MD*; Hiroshi Tada, MD; Tohru Hashimoto, MD; \\ Sachiko Ito, MD; Kohei Miyaji, MD; Shigeto Naito, MD; \\ Shigeru Oshima, MD; Koichi Taniguchi, MD
}

\begin{abstract}
Background The concentrations of atrial and brain natriuretic peptides (ANP and BNP) are elevated in patients with atrial fibrillation (AF), but the usefulness of their measurement before and after AF ablation has not been reported.

Methods and Results The concentrations of the natriuretic peptides were evaluated in 54 patients undergoing catheter ablation for drug-resistant paroxysmal and persistent $\mathrm{AF}$ without heart failure. Based on the outcome, the patients were divided into 2 groups: successful $(n=42)$ or failure $(n=12)$. All patients were asked to keep a $\log$ of the duration and frequency of their symptoms and underwent 24-h ECG monitoring at least once after the ablation. The plasma BNP and ANP concentrations, most of which were well below the heart failure range, exceeded the normal range in $69 \%$ and $26 \%$ of the patients, respectively. The BNP concentration decreased after ablation in the success group ( $49 \pm 43$ to $27 \pm 28 \mathrm{pg} / \mathrm{ml} ; \mathrm{p}<0.05$ ), however, it was unchanged in the failure group $(46 \pm 35$ to $70 \pm 37 \mathrm{pg} / \mathrm{ml} ; \mathrm{p}=0.46$ ). A value of the $\triangle \mathrm{BNP}$ (BNP after ablation-BNP before ablation) of $\leq 0 \mathrm{pg} / \mathrm{ml}$ identified a successful ablation with a sensitivity of $83 \%$ and specificity of $83 \%$. The plasma ANP concentration did not differ statistically between the 2 groups before and after the ablation.

Conclusion A moderate elevation in the BNP concentration is often found in patients with symptomatic paroxysmal and persistent AF, and a reduction in the plasma BNP concentration shortly after the ablation may indicate a successful outcome. (Circ J 2007; 71: 313-320)
\end{abstract}

Key Words: Atrial fibrillation; Atrial natriuretic peptide; Brain natriuretic peptide; Catheter ablation

A trial and brain natriuretic peptides (ANP and BNP) are neurohormonal substances that are thought to play an important role in the regulation of cardiovascular homeostasis and the circulatory blood volume!-3 Both peptides are released by the heart in response to myocardial tension and increased vascular volume, and provide an accurate diagnosis of heart failure!-3 It is well known that the concentrations of these peptides are reported to increase in patients with atrial fibrillation (AF), but without clinical heart failure ${ }^{2-8}$ and that the plasma concentrations decrease after conversion to sinus rhythm (SR) 2-7,9,10

Recently, ablation techniques involving both segmental ostial ablation to electrically isolate the pulmonary veins (PV) from the left atrium (LA) (PV isolation) and left atrial catheter ablation (LACA) have been reported as an effective treatment for drug-refractory AF!1-14 However, whether or not the natriuretic peptide levels improve after successful ablation of AF, or the role of ANP and BNP measurement in patients with $\mathrm{AF}$ and no clinical heart failure who undergo radiofrequency catheter ablation (RF-CA), have not been determined and were the aims of this study.

(Received March 29, 2006; revised manuscript received November 6 , 2006; accepted December 5, 2006)

Division of Cardiology, Gunma Prefectural Cardiovascular Center Maebashi, *Department of Cardiology, Jichi Medical School, Minamikawachi, Japan

Mailing address: Hiroshi Tada, MD, Division of Cardiology, Gunma Prefectural Cardiovascular Center, 3-12 Kameizumi, Maebashi 371-

0004, Japan. E-mail: tada.h@cvc.pref.gunma.jp

\section{Methods}

Study Population

The subjects consisted of 54 consecutive patients (46 males, 8 females; mean age, $58 \pm 9$ years) who underwent RF-CA for symptomatic AF that was resistant to at least 2 antiarrhythmic drugs. Of them, $41(76 \%)$ had paroxysmal $\mathrm{AF}$ and the remaining $13(24 \%)$ had persistent $(\mathrm{n}=1)$ or chronic $\mathrm{AF}(\mathrm{n}=12) . \mathrm{AF}$ was recorded at least once when the patient was symptomatic, and the appearance and resolution of the symptoms were related to that of $\mathrm{AF}$ in all patients with paroxysmal AF. In all patients with persistent or chronic AF, palpitations and/or dyspnea with light exercise, which were highly suggestive symptoms of AF, were observed. The mean duration of AF was $5.1 \pm 4.0$ years. In the patients with paroxysmal AF, the mean frequency of the days on which symptomatic episodes of AF occurred was $21 \pm 12$ days/month before ablation. In the patients with persistent or chronic $\mathrm{AF}$, the mean duration of $\mathrm{AF}$ was $3.8 \pm$ 3.5 years before ablation. Structural heart disease was present in 12 patients (22\%): hypertensive heart disease in 6 (50\%), nonischemic cardiomyopathy in $2(17 \%)$, coronary artery disease in $3(25 \%)$, and valvular heart disease in 1 $(8 \%)$. Among the 54 patients, $44(81 \%)$ were treated with a class I antiarrhythmic drug (disopyramide (6), cibenzoline (15), pirmenol (7), procainamide (1), pilsicainide (9), or flecainide (6)) and $5(9 \%)$ with a class III drug (amiodarone (4), sotalol (1)) up to $48 \mathrm{~h}$ before the ablation procedure. Echocardiography demonstrated a mean left ventricular 
Table 1 Clinical Characteristics and Measurement Variables of the Patients With Successful (Success Group) or Failed (Failure Group) Ablation

\begin{tabular}{|c|c|c|c|}
\hline & $\begin{array}{c}\text { Success group } \\
(n=42)\end{array}$ & $\begin{array}{l}\text { Failure group } \\
(n=12)\end{array}$ & $p$ value \\
\hline Age (years) & $59 \pm 9$ & $57 \pm 8$ & 0.6 \\
\hline Gender $(M / F)$ & $38 / 4$ & $8 / 4$ & $<0.05$ \\
\hline Heart rate (beats/min) & $68 \pm 8$ & $67 \pm 9$ & 0.8 \\
\hline Systolic blood pressure $(\mathrm{mmHg})$ & $122 \pm 17$ & $125 \pm 13$ & 0.6 \\
\hline Diastolic blood pressure $(\mathrm{mmHg}$ ) & $117 \pm 11$ & $130 \pm 11$ & 0.6 \\
\hline Paroxysmal AF/persistent AF & $32 / 10$ & $9 / 3$ & 0.9 \\
\hline Structural heart disease (\%) & 19 & 33 & 0.3 \\
\hline Left atrial diameter $(\mathrm{mm})$ & $40 \pm 7$ & $42 \pm 5$ & 0.2 \\
\hline LV ejection fraction (\%) & $64 \pm 9$ & $65 \pm 8$ & 0.7 \\
\hline LV end-diastolic dimension ( $\mathrm{mm}$ ) & $48 \pm 5$ & $49 \pm 6$ & 0.9 \\
\hline LV end-systolic dimension ( $\mathrm{mm}$ ) & $31 \pm 5$ & $32 \pm 6$ & 0.9 \\
\hline E/A ratio* & $1.2 \pm 0.8$ & $1.4 \pm 0.7$ & 0.65 \\
\hline Deceleration time $(\mathrm{ms}) *$ & $220 \pm 56$ & $198 \pm 105$ & 0.40 \\
\hline Duration of AF (years) & $5 \pm 4$ & $7 \pm 5$ & 0.1 \\
\hline \multicolumn{4}{|l|}{ Before ablation } \\
\hline Plasma ANP concentration $(\mathrm{pg} / \mathrm{ml})$ & $32 \pm 25$ & $41 \pm 32$ & 0.3 \\
\hline Prevalence of a high ANP concentration (paroxysmal $A F / p e r s i s t e n t ~ A F$ ) & $5 / 5$ & $2 / 2$ & 0.6 \\
\hline Plasma BNP concentration $(\mathrm{pg} / \mathrm{ml})$ & $49 \pm 43$ & $45 \pm 34$ & 0.8 \\
\hline Prevalence of a high BNP concentration (paroxysmal $A F /$ persistent $A F$ ) & $18 / 9$ & $7 / 3$ & 0.8 \\
\hline \multicolumn{4}{|l|}{ Sinus rhythm at NP measurement } \\
\hline Before ablation (\%) & $32 / 42(76 \%)$ & $7 / 12(58 \%)$ & 0.2 \\
\hline After ablation (\%) & $42 / 42(100 \%)$ & $6 / 12(50 \%)$ & $<0.0001$ \\
\hline \multicolumn{4}{|l|}{ Catheter ablation } \\
\hline$P V$ isolation/LACA ( $n)$ & $27 / 15$ & $8 / 4$ & 0.9 \\
\hline Duration of RF energy ( $\mathrm{min}$ ) & $32 \pm 12$ & $31 \pm 12$ & 0.8 \\
\hline Electrically isolated PVs $(n /$ case $)$ & $3.5 \pm 0.6$ & $3.6 \pm 0.5$ & 0.7 \\
\hline \multicolumn{4}{|l|}{ Medication (\%) } \\
\hline ARBs & $18(43)$ & $4(33)$ & 0.6 \\
\hline ACEIs & $2(4)$ & $1(8)$ & 0.6 \\
\hline Calcium-channel blockers & $9(21)$ & $2(17)$ & 0.7 \\
\hline$\beta$-blockers & $7(17)$ & $2(17)$ & 1.0 \\
\hline
\end{tabular}

Values are mean \pm standard deviation.

Heart rate and blood pressure were measured at the time of the natriuretic peptide measurements.

$A F$, atrial fibrillation; $L V$, left ventricular; $A(B) N P$, atrial (brain) natriuretic peptide; $N$, natriuretic peptides; $P V$, pulmonary vein; $L A(C A)$, left atrial (catheter ablation); RF, radiofrequency; ARBs, angiotensin II receptor blockers; ACEIs, angiotensin-converting enzyme inhibitors.

*Analysis in 41 patients with paroxysmal $A F$ ( $n=32$ in the success group; $n=9$ in the failure group).

ejection fraction (LVEF) of $64 \pm 9 \%$ and mean LA diameter (LAd) of $40 \pm 6 \mathrm{~mm}$, and none had symptoms suggestive of overt heart failure. None of the patients in this study had overt renal dysfunction (serum creatinine $>1.2 \mathrm{mg} / \mathrm{dl}$ ).

\section{Study Protocol}

Each subject gave informed consent for their participation. All antiarrhythmic drugs were discontinued at least $48 \mathrm{~h}$ before the blood sampling and the ablation procedure. After the heart rate and blood pressure measurements, blood samples from a peripheral vein were taken from all patients $12-24 \mathrm{~h}$ before RF-CA to evaluate the plasma concentrations of ANP and BNP. After the ablation procedure, the patients underwent a follow-up ( 2 weeks after the PV isolation, then every 1-2 months at the cardiology clinic). To confirm recurrence of AF, the 12-lead ECG was recorded on each visit to the clinic, and 24-h Holter monitoring was also recorded at least once during the follow-up period. Recurrence of AF was defined as recurrence of symptoms suggestive of tachycardia and an episode of AF documented on the 12-lead ECG or 24-h Holter monitoring during the follow-up period. Three months after the ablation procedure, the patients were divided into 2 groups on the basis of AF recurrence: success group $(n=42)$ and failure group ( $n=12$; Table 1). Successful RF-CA was defined as no recurrence of $\mathrm{AF}$ without any antiarrhythmic drugs or a $>90 \%$ reduction in the frequency of symptomatic episodes of AF with or without antiarrhythmic drugs that had been ineffective before the procedure! ${ }^{11}$ The plasma concentrations of the natriuretic peptides were measured 3 months after the ablation procedure. In the cases of a repeat ablation procedure, successful or failed ablation was determined and the plasma concentrations of the natriuretic peptides were measured 3 months after the repeat procedure. The change in the concentration of the natriuretic peptides $(\triangle \mathrm{BNP}$ or $\triangle \mathrm{ANP}$ ) was defined as the difference in the plasma concentration measured after the ablation procedure from that measured before the procedure. Echocardiographic examinations were performed in all patients just before the ablation procedure and at the same time as blood sampling after the procedure to assess the LVEF, left ventricular end-diastolic dimension (LVEDd), left ventricular end-systolic dimension (LVESd) and LAd. The LVEF, LVEDd and LVESd were evaluated by Teichholz's rule! ${ }^{15}$ In 41 patients with paroxysmal $\mathrm{AF}$ before the ablation, the transmitral peak $\mathrm{E}$ and A wave velocity was recorded, and the E/A ratio and deceleration time were assessed by pulse-wave Doppler, with the sample volume placed between the mitral valve leaflets. In 28 of the $54(52 \%)$ patients, the natriuretic peptides were also measured during long-term follow-up $(12 \pm 4$ months after the ablation procedure). To avoid any positive or negative inotropic cardiac effects of drugs such 
as digitalis, $\beta$-blockers, calcium-channel blockers, angiotensin-converting enzyme inhibitors or angiotensin II receptor blockers, those drugs were continued during the follow-up period at the same dosage as before the ablation procedure.

\section{Measurement of Plasma Concentrations of ANP and BNP}

After the patient had been supine for at least $30 \mathrm{~min}$, a blood sample was drawn from a peripheral vein into chilled disposable tubes containing aprotinin (500 karikrein inactivator $\mathrm{U} / \mathrm{ml}$ ). The tubes were quickly placed on ice and centrifuged at $3,000 \mathrm{rpm}$ for $15 \mathrm{~min}$ at $4^{\circ} \mathrm{C}$ and the plasma was stored at $-30^{\circ} \mathrm{C}$ until it was assayed. The plasma ANP and BNP concentrations were measured with specific immunoradiometric assays for human ANP (Shionoria ANP kit, Osaka, Japan) and human BNP (Shionoria BNP kit, Osaka, Japan) ${ }^{16,17}$ The assays had a sensitivity of $2 \mathrm{pg} / \mathrm{ml}$, and inter- and intra-assay coefficients of variation of $6.1 \%$ and $5.2 \%$, respectively ${ }^{17}$ The normal reference values of the plasma BNP and ANP concentrations in the Japanese are $<18.4 \mathrm{pg} / \mathrm{ml}$ and $<43.0 \mathrm{pg} / \mathrm{ml}$, respectively 16

\section{Ablation Procedure}

Two different ablation techniques were carried out for the treatment of the AF: the initial 35 patients $(65 \%)$ underwent PV isolation, ${ }^{1-13}$ and the remaining 19 (35\%) underwent a combined approach of LACA and PV isolation as previously described.11,14 Right femoral venous access was obtained and a multipolar electrode catheter was introduced into the distal coronary sinus. After transseptal catheterization, a 7Fr decapolar ring catheter with 1-mm interelectrode spacing of paired electrodes at intervals of 4.5 or $6.0 \mathrm{~mm}$ (Lasso $^{\mathrm{TM}}$, Biosense Webster, Diamond Bar, CA, USA) was inserted into the LA and positioned inside the PV within $5 \mathrm{~mm}$ of the ostium.

In the PV isolation, after positioning the Lasso ${ }^{\mathrm{TM}}$ catheter at the ostia, catheter ablation was performed during SR or atrial pacing from the distal coronary sinus. ${ }^{13}$ After segmental isolation of the left superior, right superior and left inferior PVs was attempted, an additional isolation of the right inferior PV was also attempted whenever possible. Radiofrequency energy was delivered using a maximum power of $30 \mathrm{~W}$ and maximum electrode-tissue interface temperature of $52-55^{\circ} \mathrm{C}$. The applications of energy were 60-90 s in duration. The endpoint for ablation was the elimination of the PV potentials at all Lasso ${ }^{\mathrm{TM}}$ catheter recording sites! 11,13

In the LACA procedure, 2 Lasso $^{\mathrm{TM}}$ catheters positioned inside the ipsilateral PVs within $5 \mathrm{~mm}$ of the ostia were necessary to record the PV potentials. ${ }^{14}$ A 4-mm-tip deflectable catheter (Navistar, Biosense Webster) was advanced into the LA and a 3-dimensional shell representing the LA was constructed by using an electroanatomic mapping system (CARTO, Biosense Webster). LA linear ablation was performed to encircle the left- and right-sided PVs $1-2 \mathrm{~cm}$ from their ostia, with additional lines in the posterior LA between the 2 encircling lesions and at the mitral isthmus!1,14 Radiofrequency energy was delivered at a maximum power output of $35-40 \mathrm{~W}$ and target temperature of $55^{\circ} \mathrm{C}$. At the tagged sites, RF energy was applied until the maximum local electrogram amplitude decreased by $\geq 50 \%$ or to $<0.1 \mathrm{mV}$. When there were any PV potentials within the PVs, PV isolation was performed as previously described 14 In patients with paroxysmal $\mathrm{AF}$, induction of $\mathrm{AF}$ was performed by burst pacing from the coronary sinus.

\section{Statistical Analysis}

Continuous variables are expressed as the mean \pm SD. Continuous variables were compared with the t-test or 1-way ANOVA coupled with Scheffe's test, as appropriate. Categorical variables were compared by chi-square analysis. Correlations between variables were assessed by Pearson's linear correlation and tested using Fisher's z transformation. To assess the reduction in the BNP concentration from using class I antiarrhythmic drugs after ablation, a MANCOVA was performed. A value of $\mathrm{p}<0.05$ was considered statistically significant.

\section{Results}

\section{$R F-C A$}

RF-CA (PV isolation or LACA) was performed in all 54 patients. No potential complications occurred in any of the patients during either the procedure or follow-up. In the 41 patients with paroxysmal AF, no AF was induced by programmed atrial pacing at the end of the ablation procedure. In 5 patients, a repeat ablation procedure for recurrent $\mathrm{AF}$ was performed $10 \pm 7$ days later. Three months after the ablation procedure, 42 patients were classified into the success group, and the remaining 12 into the failure group according to the criteria (Table 1 ). Of the 5 patients undergoing a repeat ablation procedure, 4 were classified as successful and 1 as a failure. The duration of the RF energy applications and number of completely isolated PVs did not differ between the 2 groups (Table 1 ).

\section{Characteristics of the Success and Failure Groups Before Ablation}

Although the ratio of males to females was higher in the success group than in the failure group $(\mathrm{p}<0.05)$, no significant difference was found between the success and failure groups in age, heart rate or blood pressure at the time of the natriuretic peptide measurements, prevalence of structural heart disease, RF-CA technique used (PV isolation or LACA), LAd, LVEDd, LVESd, LVEF, E/A ratio, deceleration time or duration of AF (Table 1). In the success group, complete elimination of AF without any antiarrhythmic drugs occurred in $24(57 \%)$ of 42 patients, and a $>90 \%$ reduction in the frequency of $\mathrm{AF}$ with or without antiarrhythmic drugs was observed in 18 patients: 9 had paroxysmal AF and the remaining 9 had chronic AF. In the 9 patients with paroxysmal AF, the frequency of symptomatic episodes of AF per month decreased from 13.9 \pm 10.8 to $0.9 \pm 0.5$ after ablation $(\mathrm{p}<0.01)$. The mean duration of $\mathrm{AF}$ attacks per episode also decreased from $5.3 \pm 7.3 \mathrm{~h}$ to $2.0 \pm 1.8 \mathrm{~h}$ after ablation $(\mathrm{p}=0.20)$. In the remaining 9 patients with chronic AF, the frequency of AF episodes after ablation was $1.5 \pm 1.1$ per month and the duration was $5.3 \pm 2.4 \mathrm{~h}$ per episode.

\section{Plasma BNP and ANP Concentrations Before Ablation}

Before ablation, the plasma BNP and ANP concentrations exceeded the normal range (high BNP and ANP concentrations) in $37(69 \%)$ and 14 (26\%), respectively, of the 54 patients. The plasma BNP or ANP concentration before ablation did not differ between the 2 groups (Table 1 ). The plasma BNP concentration before ablation significantly correlated with the LAd ( $\mathrm{p}=0.02 ; \mathrm{r}=0.32)$, but not with the LVEF ( $p=0.06 ; r=0.26)$. No significant correlation was found between the plasma ANP concentration and LAd $(\mathrm{p}=0.72 ; \mathrm{r}=0.05)$ or $\operatorname{LVEF}(\mathrm{p}=0.47 ; \mathrm{r}=0.1)$. 


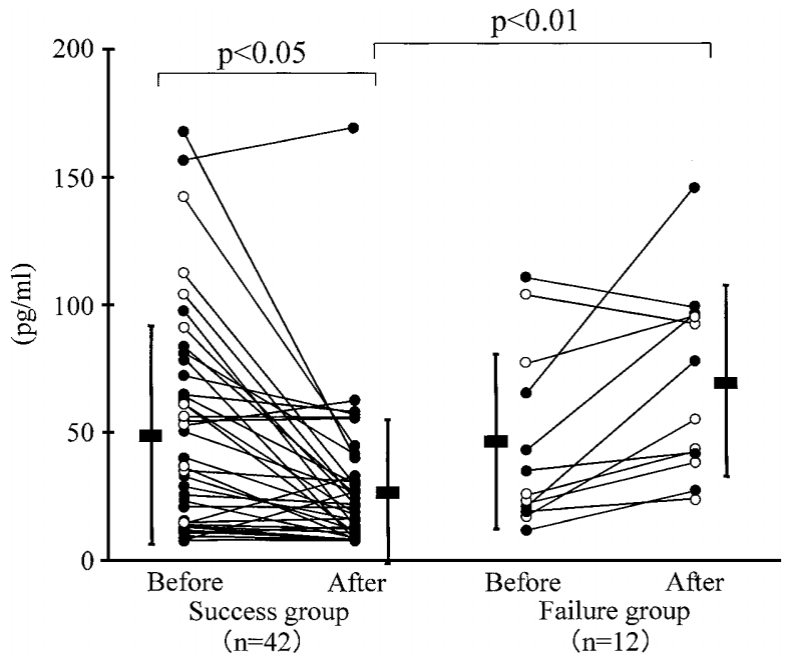

Fig 1. Plasma brain natriuretic peptide (BNP) concentrations before and after catheter ablation. Patients in (O) normal sinus rhythm and $(\bigcirc)$ atrial fibrillation during the plasma BNP concentration measurement.

\section{Change in the Plasma Concentration of BNP Before and After RF-CA in the Success and Failure Groups}

In the 42 patients in the success group, the plasma BNP concentration decreased after ablation $(49 \pm 43 \mathrm{pg} / \mathrm{ml}$ to $27 \pm 28 \mathrm{pg} / \mathrm{ml} ; \mathrm{p}<0.05 ;$ Fig 1$)$. However, in the 12 patients in the failure group, it increased after ablation $(46 \pm 35 \mathrm{pg} / \mathrm{ml}$ to $70 \pm 37 \mathrm{pg} / \mathrm{ml})$, but there was no significant difference $(\mathrm{p}=$ 0.46; Fig 1). A decrease in the plasma BNP concentration occurred after ablation in $32(76 \%)$ patients in the success group and in 2 (17\%) patients in the failure group, and there was a significant difference in its prevalence among the 2 groups $(\mathrm{p}<0.001)$.

In the success group, 32 patients had $\mathrm{AF}$ and the remaining 10 were in SR at the time of blood sampling before the ablation, and there was no significant difference in the plasma BNP concentrations between the patients with $\mathrm{AF}$ and those with SR ( $\mathrm{p}=0.07$; Fig 1, Table 1). The plasma BNP concentration decreased significantly after ablation in both the patients who had AF $(71 \pm 40 \mathrm{pg} / \mathrm{ml}$ to $32 \pm 18$ $\mathrm{pg} / \mathrm{ml} ; \mathrm{p}<0.05)$ and those who were in SR at the time of blood sampling before the ablation $(43 \pm 42 \mathrm{pg} / \mathrm{ml}$ to $25 \pm 31$ $\mathrm{pg} / \mathrm{ml} ; \mathrm{p}<0.01$; Fig 1$)$. However, in the failure group, no significant difference was observed in the plasma BNP concentrations between the patients who had $\mathrm{AF}(\mathrm{n}=5)$ and those who were in $\mathrm{SR}(\mathrm{n}=7)$ at the time of blood sampling before the ablation ( $\mathrm{p}=0.80$; Fig 1 , Table 1$)$. After the ablation, there was no decrease in the BNP concentration in either the patients who had AF or in those who were in SR at the time of blood sampling before the ablation (AF: $49 \pm 39 \mathrm{pg} / \mathrm{ml}$ to $65 \pm 27 \mathrm{pg} / \mathrm{ml}, \mathrm{p}=0.12$; SR: $44 \pm 35 \mathrm{pg} / \mathrm{ml}$ to $73 \pm 45 \mathrm{pg} / \mathrm{ml}, \mathrm{p}=0.06$ ). Furthermore, no significant difference was found in the plasma BNP concentrations of the patients who had AF (n=6; $58 \pm 30 \mathrm{pg} / \mathrm{ml})$ and those who were in SR at the time of blood sampling after the ablation $(\mathrm{n}=6 ; 82 \pm 43 \mathrm{pg} / \mathrm{ml}, \mathrm{p}=0.29)$.

In the success group, a high BNP concentration was observed in $27(64 \%)$ patients before ablation, and it normalized in $8(30 \%)$ of them after ablation. In the failure group, $10(83 \%)$ patients had a high BNP concentration before ablation, but none demonstrated normalization after ablation ( $\mathrm{p}=0.05$ vs the success group). After the ablation

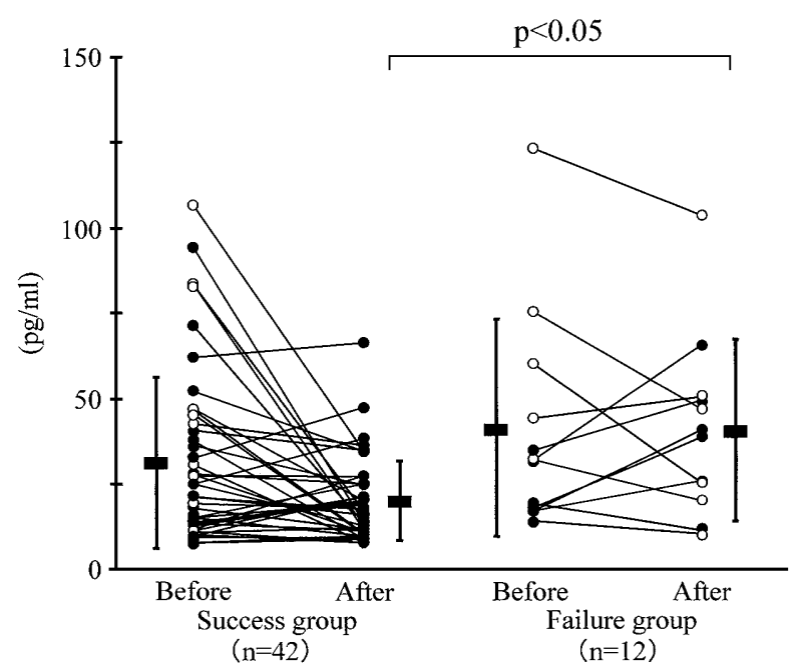

Fig 2. Plasma atrial natriuretic peptide (ANP) concentrations before and after catheter ablation. Patients in (O) normal sinus rhythm and ( $\bigcirc$ ) atrial fibrillation during the plasma ANP concentration measurement.

procedure, 23 of 54 patients were treated with randomly selected class I antiarrhythmic drugs (disopyramide (2), cibenzoline (7), pirmenol (6), pilsicainide (3), flecainide (5)) that had been given before the ablation, but none had an effect on the reduction in plasma BNP concentration when given after the ablation $(\mathrm{p}=0.40)$. At the time of the natriuretic peptide measurements after ablation, 18 of 23 (78\%) patients were treated with the same antiarrhythmic drugs that had been given up to $48 \mathrm{~h}$ before the ablation, and the remaining $5(22 \%)$ were treated with different drugs.

\section{Change in the Plasma Concentration of ANP Before and} After RF-CA in the Success and Failure Groups

The plasma ANP concentration did not differ between the 2 groups before and after ablation $(32 \pm 25 \mathrm{pg} / \mathrm{ml}$ to $20 \pm$ $12 \mathrm{pg} / \mathrm{ml}$ in the success group, $41 \pm 32 \mathrm{pg} / \mathrm{ml}$ to $41 \pm 26 \mathrm{pg} / \mathrm{ml}$ in the failure group; Fig 2). However, the ANP concentration after ablation in the success group was lower than that in the failure group $(\mathrm{p}<0.05$; Fig 2$)$. The prevalence of the patients who had a decrease in the plasma ANP concentration after ablation was 26 of $42(62 \%)$ in the success group and 6 of $12(50 \%)$ in the failure group $(\mathrm{p}=0.46)$.

In both groups, the plasma ANP concentration before the ablation was greater in the patients who had $\mathrm{AF}$ at the time of blood sampling than in those who were in SR (success group: $\mathrm{AF}, \mathrm{n}=10,50 \pm 31 \mathrm{pg} / \mathrm{ml}, \mathrm{SR}, \mathrm{n}=32,26 \pm 20 \mathrm{pg} / \mathrm{ml}, \mathrm{p}<$ 0.01 ; failure group: $\mathrm{AF}, \mathrm{n}=5,67 \pm 35 \mathrm{pg} / \mathrm{ml}, \mathrm{SR}, \mathrm{n}=7,22 \pm$ $8 \mathrm{pg} / \mathrm{ml}, \mathrm{p}<0.01$; Fig 2). In the success group, the plasma ANP concentration decreased significantly after ablation in the patients who had AF at the time of blood sampling before the ablation $(50 \pm 31 \mathrm{pg} / \mathrm{ml}$ to $20 \pm 10 \mathrm{pg} / \mathrm{ml}, \mathrm{p}<0.05)$. However, it did not decrease significantly in the patients who were in SR at the time of blood sampling before the ablation $(26 \pm 20 \mathrm{pg} / \mathrm{ml}$ to $20 \pm 13 \mathrm{pg} / \mathrm{ml}, \mathrm{p}=0.11$; Fig 2$)$. On the other hand, in the failure group, there was no significant change in the ANP levels after ablation in either the patients with $\mathrm{AF}(\mathrm{n}=5 ; 67 \pm 35 \mathrm{pg} / \mathrm{ml}$ to $50 \pm 33 \mathrm{pg} / \mathrm{ml}, \mathrm{p}=0.07)$ or those in $\mathrm{SR}(\mathrm{n}=7 ; 22 \pm 8 \mathrm{pg} / \mathrm{ml}$ to $35 \pm 20 \mathrm{pg} / \mathrm{ml}, \mathrm{p}=0.06)$ at the time of blood sampling before the ablation (Fig 2). Furthermore, there was no significant difference in the plasma ANP concentration between the patients with AF 
Table 2 Sensitivity, Specificity and Predictive Accuracy for Successful Catheter Ablation

\begin{tabular}{lcccc}
\hline \hline Criterion & $\begin{array}{c}\text { Sensitivity } \\
(\%)\end{array}$ & $\begin{array}{c}\text { Specificity } \\
(\%)\end{array}$ & $\begin{array}{c}P P V \\
(\%)\end{array}$ & $\begin{array}{c}\text { NPV } \\
(\%)\end{array}$ \\
\hline Plasma BNP concentration & & & & \\
$\Delta B N P \leq 0 \mathrm{pg} / \mathrm{ml}$ & 83 & 83 & 95 & 59 \\
$\Delta B N P \leq-20 \mathrm{pg} / \mathrm{ml}$ & 38 & 100 & 100 & 32 \\
$\Delta B N P \leq 20 \mathrm{pg} / \mathrm{ml}$ & 100 & 33 & 84 & 100 \\
Plasma ANP concentration & & & & 30 \\
$\Delta A N P \leq 0 \mathrm{pg} / \mathrm{ml}$ & 62 & 58 & 78 & 22 \\
$\Delta A N P \leq-10 \mathrm{pg} / \mathrm{ml}$ & 33 & 67 & 83 & 50 \\
$\Delta A N P \leq 10 \mathrm{pg} / \mathrm{ml}$ & 90 & 33 & & \\
\hline
\end{tabular}

$N(P) P V$, negative (positive) predictive accuracy; $\triangle A(B) N P$, difference in the plasma concentration of $A(B) N P$ after the ablation procedure from that before the procedure. Other abbreviations see in Table 1.

$(\mathrm{n}=6 ; 43 \pm 34 \mathrm{pg} / \mathrm{ml})$ and those with SR at the time of blood sampling after the ablation $(\mathrm{n}=6 ; 39 \pm 19 \mathrm{pg} / \mathrm{ml}, \mathrm{p}=0.80)$.

A high ANP concentration before ablation was found in $10(24 \%)$ patients in the success group and in $4(33 \%)$ in the failure group. In $9(90 \%)$ of the 10 patients who had a high ANP concentration before ablation, it decreased to the normal range after ablation. However, in the failure group, only $1(25 \%)$ patient had normalization of the plasma ANP concentration after ablation ( $\mathrm{p}<0.05$ vs the success group).

\section{Sensitivity and Specificity of the Criteria}

The sensitivity, specificity and predictive accuracy of $\triangle \mathrm{BNP}$ and $\triangle \mathrm{ANP}$ for identification of successful ablation are shown in Table 2. The $\triangle \mathrm{BNP}$ was smaller in the success group $(-23 \pm 35 \mathrm{pg} / \mathrm{ml})$ than in the failure group $(24 \pm 28 \mathrm{pg} / \mathrm{ml}$, $\mathrm{p}<0.0001$; Fig $3 \mathrm{~A}$ ). The $\Delta \mathrm{BNP}$ of $\leq 0 \mathrm{pg} / \mathrm{ml}$ predicted successful ablation with a sensitivity of $83 \%$, specificity of $83 \%$, positive predictive accuracy of $95 \%$, and negative predictive accuracy of $59 \%$. The $\triangle \mathrm{ANP}$ was also smaller in the success group $(-12 \pm 25 \mathrm{pg} / \mathrm{ml})$ than in the failure group $(0 \pm 22 \mathrm{pg} / \mathrm{ml})$; however, there was no significant difference between the 2 groups ( $\mathrm{p}=0.14$; Fig $3 \mathrm{~B})$. The $\triangle \mathrm{ANP}$ of $\leq 0 \mathrm{pg} / \mathrm{ml}$ predicted successful ablation with a sensitivity of $62 \%$, specificity of $50 \%$, positive predictive accuracy of $82 \%$, and negative predictive accuracy of $29 \%$. The $\triangle \mathrm{BNP}$ values in the success group were comparable for the patients who had AF and those who were in SR at the time of blood sampling before ablation (AF: $\mathrm{n}=10,-39 \pm 43 \mathrm{pg} / \mathrm{ml}$; SR: $n=32,-18 \pm 31 \mathrm{pg} / \mathrm{ml}, \mathrm{p}=0.10$; Fig $3 \mathrm{~A}$ ). However, the $\triangle$ ANP values were less in the patients who had $\mathrm{AF}(\mathrm{n}=10$, $-10 \pm 31 \mathrm{pg} / \mathrm{ml}$ ) than in those who were in SR at the time of blood sampling before the ablation $(\mathrm{n}=32,-6 \pm 20 \mathrm{pg} / \mathrm{ml}$, $\mathrm{p}<0.01$; Fig 3B).

Change in the LAd, LVEDd, LVESd and LVEF Before and After RF-CA in the Success and Failure Groups

In the success group, the LAd significantly decreased
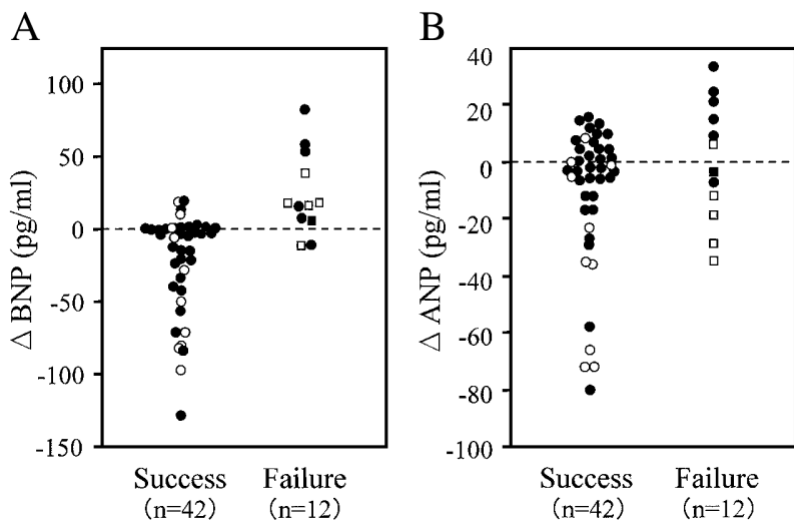

Fig 3. (A) Difference in the plasma concentrations of brain natriuretic peptide after the ablation procedure compared with before the procedure $(\triangle \mathrm{BNP})$ in the success and failure groups. (B) Difference in the plasma concentration of atrial natriuretic peptide after the ablation procedure compared with before the procedure $(\triangle \mathrm{ANP})$ in the success and failure groups. Patients who were in $(\mathbf{O})$ normal sinus rhythm (SR) or $(\bigcirc)$ atrial fibrillation (AF) during the natriuretic peptide measurements both before and after the ablation. Patients who were in (ם) SR during natriuretic peptide measurements before the ablation but in $\mathrm{AF}$ after the ablation. ( $\square$ ) Patients who had AF during the natriuretic peptide measurements both before and after the ablation.

after the ablation procedure $(39 \pm 6 \mathrm{~mm}$ to $37 \pm 6 \mathrm{~mm}, \mathrm{p}<$ $0.05)$, but did not differ in the failure group $(41 \pm 4 \mathrm{~mm}$ to $43 \pm 5 \mathrm{~mm}, \mathrm{p}=0.09$ ). No significant difference was observed in the LVEF before and after the ablation procedure in either the success $(64 \pm 9 \%$ to $65 \pm 7 \%, \mathrm{p}=0.65)$ or failure $(62 \pm 5 \%$ to $61 \pm 7 \%, \mathrm{p}=0.36)$ group. As for the LVEDd and LVESd, no significant difference was detected before or after ablation in either the failure or success group (data not shown).

Table 3 Plasma Concentrations of the NP Measured Before and 3 Months After the Ablation Procedure and During Long-Term Follow-up (12 \pm 4 Months) in 28 Patients

\begin{tabular}{lccc}
\hline \hline & Before ablation & 3 months after ablation & Long-term follow-up \\
\hline Plasma BNP concentration $(\mathrm{pg} / \mathrm{ml})$ & & & \\
Success group $(n=20)$ & $52 \pm 44$ & $20 \pm 16$ & $21 \pm 16^{*}$ \\
Failure group $(n=8)$ & $39 \pm 34$ & $63 \pm 31$ & $73 \pm 55$ \\
Plasma ANP concentration $(\mathrm{pg} / \mathrm{ml})$ & & & \\
Success group $(n=20)$ & $31 \pm 24$ & $20 \pm 11$ & $20 \pm 10$ \\
Failure group $(n=8)$ & $45 \pm 39$ & $39 \pm 29$ & $48 \pm 45$ \\
\hline
\end{tabular}

Values are mean \pm standard deviation.

${ }^{*} p<0.05$ vs the failure group in long-term follow-up. Abbreviations see in Table 1. 


\section{Plasma Concentration of the Natriuretic Peptides During Long-Term Follow-up}

In $28(52 \%)$ of the 54 patients, of whom 20 were in the success and 8 were in the failure group, the natriuretic peptides were measured $12 \pm 4$ months after the ablation procedure (Table 3 ). In each patient, the frequency of symptomatic AF episodes at the time of the natriuretic peptide measurements during long-term follow-up was almost the same as at 3 months after the ablation procedure. In the 20 success-group patients, the plasma BNP concentration at long-term follow-up was lower than that in the 8 failuregroup patients $(\mathrm{p}<0.05)$, and there was a similar tendency for the plasma ANP concentration $(\mathrm{p}=0.19)$.

\section{Discussion}

In this study we found that the plasma BNP and ANP concentrations, most of which were well below the heart failure range, 18 (1) exceeded the normal range in $69 \%$ and $26 \%$, respectively, of patients with symptomatic AF without clinical heart failure, and (2) decreased after ablation in most patients with a successful ablation, but did not in most patients with a failed ablation. We also found that $\triangle \mathrm{BNP}$ of $\leq 0 \mathrm{pg} / \mathrm{ml}$ could predict successful ablation with modest accuracy. These results indicate that the plasma concentrations of the natriuretic peptides, especially BNP, are often elevated in patients with symptomatic AF, and that a reduction in the plasma BNP concentration shortly after the ablation may be a marker of successful ablation.

In the present study, the plasma concentrations of the natriuretic peptides measured approximately 1 year after ablation did not differ from those at 3 months after ablation in selected patients whose frequency of AF episodes did not change dramatically during the follow-up period; that is, improvement in the plasma concentrations of the natriuretic peptides lasted in the patients with a successful AF ablation, but there was no difference in the concentrations between before and 3 months after the ablation in the patients with a failed ablation, which indicates that a decrease in the plasma concentration of BNP could reflect an improvement in $\mathrm{AF}$, and that BNP measurement may be useful for predicting successful ablation during the long-term follow-up period.

\section{Proposed Mechanisms of High ANP and BNP Concentrations During AF and Decreased \\ Concentrations After Successful RF-CA}

ANP is mainly secreted from the atria secondary to atrial stretch, and its plasma concentrations are elevated in patients with heart failure!, 2 However, it is also well known that ANP is increased in the setting of atrial tachyarrhythmias, including AF, independent of the LAd 19 The elevated concentration of ANP in the peripheral plasma obtained during persistent $\mathrm{AF}$ is considered to be caused by the loss of atrial contraction and the rapid ventricular rate, which leads to an increased central volume loading and atrial stretch? The effect of restoring SR after persistent AF on the plasma ANP concentration has been investigated: (1) the plasma ANP concentration immediately before electrical cardioversion was on average increased compared with normal, indicating that the surge in ANP was not confined to the onset of AF but persisted beyond the acute stage, (2) restoration of SR caused a rapid lowering of the plasma ANP concentration in most patients, in conjunction with filling pressures, and (3) in the setting of long-standing AF, time-dependent structural and functional effects may have an affect on the arrhythmia. Long-standing AF, by causing atrial structural remodeling and eventually irreversible damage, leads to a reduced capacity for ANP production?

Because the total number of patients with persistent or chronic AF in the present study was small (24\%) and because the duration of AF in those patients was not long, the ANP production capacity in patients with persistent or chronic AF may not have been severely impaired in the present study. However, an elevated plasma ANP concentration was observed in only $26 \%$ of the patients before AF ablation, and 39 of the $54(72 \%)$ patients had paroxysmal $\mathrm{AF}$ and were in SR at the time of ANP measurement before ablation (Table 1). Recent studies have demonstrated that the ANP concentration is elevated in patients with persistent $\mathrm{AF}$, and furthermore, a few studies have been performed in patients with lone paroxysmal AF, indicating that the plasma ANP concentration might not be remarkably elevated in paroxysmal AF patients who do not have clinical heart failure. Thomas et al showed that the plasma ANP concentration in persistent AF significantly and immediately dropped at $4 \mathrm{~h}$ after DC cardioversion and recovered by day 7 to approximately the level of that at the intermediate baseline and $4 \mathrm{~h}$ after the cardioversion.$^{10}$ It is thought that the drop in the ANP concentration just after cardioversion to SR is caused by the initial stunning of both the mechanical and endocrine functions. In patients with paroxysmal $\mathrm{AF}$ with frequent attacks, frequent restoration to SR may cause the same conditions as those observed shortly after DC cardioversion. These mechanisms may be responsible for the low frequency of a high ANP concentration in the present study.

The BNP is predominantly released from the ventricles in response to volume expansion and pressure overload, and an increase in the plasma BNP concentration is considered to reflect ventricular structural and functional abnormalities, 1,3 The plasma concentration of BNP has emerged as a useful, cost-effective biomarker for the diagnosis and prognosis of heart failure 1,3 However, the possible use of the $\mathrm{BNP}$ as a biomarker for non-heart failure mechanisms, preclinical disease, and other pathologic states of myocardial disease, including coronary endothelial dysfunction, myocardial ischemia and arrhythmias, has only been recently reported? Recent studies have demonstrated that the plasma BNP concentration is increased in patients with AF and normal ventricular function compared with controls, and that the elevated BNP level decreased significantly after restoration of $\mathrm{SR}$ ? A recent study also demonstrated that moderate elevations in the plasma BNP level, as low as just $20 \mathrm{pg} / \mathrm{ml}$, which is well below the threshold of the diagnosis of heart failure, were associated with a risk of AF! ${ }^{18}$ Increased atrial stretch during AF is likely to be responsible for the elevated levels of plasma BNP associated with increased LA volume, because BNP is released primarily from the atria in the non-heart-failure setting?,20 In the present study, approximately $70 \%$ of the patients had a high BNP concentration before ablation, and the plasma BNP concentration correlated with the LAd. Furthermore, the prevalence of patients in whom the plasma BNP concentration decreased after ablation was significantly higher in the success group than in the failure group. The usefulness of plasma BNP measurement for predicting successful AF elimination or AF occurrence after cardiac surgery has been reported, ${ }^{21-23}$ so in patients with symptomatic AF, but without heart failure, the plasma BNP concentration may 
reflect a rhythm disturbance.

\section{Previous Studies}

Several studies have shown that AF raises the plasma levels of the natriuretic peptides and that the concentrations drop after a successful cardioversion or Maze procedure? $, 9,10,21-23$ However, no studies have examined the effect of RF-CA on the natriuretic peptide concentrations in patients with $\mathrm{AF}$.

\section{Clinical Implications}

We measured the natriuretic peptide concentrations before and after RF-CA in patients with symptomatic AF without heart failure. The measured concentrations often exceeded the normal range, although most were well below the diagnosis threshold of heart failure ${ }^{18}$ Our data indicated that a decrease in the natriuretic peptide concentration, especially the BNP level, is associated with successful AF ablation. Conversely, no decrease in the plasma BNP concentration after ablation may indicate a failed ablation, and possible AF recurrence. The results of the present and previous studies ${ }^{2-10,21-23}$ suggest that measuring the plasma natriuretic peptide concentrations, especially the BNP level, may assist in diagnosing the presence or degree of $\mathrm{AF}$, and that a decrease in the plasma BNP concentration after RFCA may be a useful marker for predicting elimination of attacks in patients with AF but no heart failure.

\section{Study Limitations}

First, this study compared the concentration of natriuretic peptides by taking a blood sample once before ablation. In the present study, all of the patients with paroxysmal AF were highly symptomatic with many attacks before ablation, and often had high levels of the natriuretic peptides. However, whether or not these can precisely reflect the frequency of the AF attacks might be obscure, especially in patients with paroxysmal AF. A recent study indicated that the intra-individual variation in the plasma BNP concentration was considerable, and that $44 \%$ of patients with hypertension had a difference in the plasma BNP concentration of at least $10 \mathrm{pg} / \mathrm{ml}^{24}$ Because $22 \%$ of the patients in the present study had structural heart disease, a high variation in the BNP concentration might have been revealed by repeat measurements before and after ablation. Therefore, we should have measured the levels of the natriuretic peptides several times before and after ablation. Second, the clinical efficacy of RF-CA was based on the symptoms reported by the patients. Because all of the patients in this study had highly symptomatic AF before ablation, the absence of symptomatic AF after the ablation procedure might have been considered by them as an acceptable clinical endpoint. Although ambulatory Holter monitoring was routinely performed once in all patients during the followup, asymptomatic episodes of AF after ablation might have been missed 25 Third, the detailed diastolic function of the left ventricle and its relationship to the natriuretic peptide levels were not examined in this study. It was difficult to precisely assess the diastolic function in these patients because a considerable number of them had $\mathrm{AF}$ at the time of echocardiography. However, there is a fair possibility in this study that the improvement in diastolic function after successful ablation might have been related to the significant reduction in the plasma BNP concentration.26 Fourth, the lack of a correlation between the BNP concentration and LVEF might have been related to the small number of patients studied. Finally, in selected patients, the natriuretic peptide concentrations measured approximately 12 months after the ablation were the same as those at 3 months after the procedure in each group, which suggests the possibility that the measurement of natriuretic peptide concentrations can be used as a predictor of $\mathrm{AF}$ ablation during long-term follow-up. Our results also may indicate that (1) a decreased plasma BNP concentration after ablation predicts a successful ablation, irrespective of the basal cardiac rhythm before ablation, (2) a successful or failed ablation plays a more significant role in the decreased plasma BNP concentration than the basal cardiac rhythm at the time of blood sampling, and (3) the plasma ANP concentration seems to be more influenced by the cardiac rhythm (AF or SR) at the time of blood sampling than by the plasma BNP concentration. However, our sample size was relatively small and the follow-up period after ablation procedure was relatively short, so further studies with a larger number of patients and a longer follow-up period may be needed to confirm and enhance our results.

\section{Conclusions}

The plasma BNP concentration exceeded the normal range in approximately $70 \%$ of patients with $\mathrm{AF}$, and in most patients it decreased shortly after successful AF ablation. A reduction in the plasma BNP concentration after ablation may indicate a successful procedure.

\section{Acknowledgments}

This work was supported by a Research Grant for Cardiovascular Diseases (14C-2) from the Ministry of Health, Labor and Welfare, Japan and by a grant from the Gunma Prefecture Government.

\section{References}

1. Levin ER, Gardner DG, Samson WK. Natriuretic peptides. $N$ Engl $J$ Med 1998; 339: 321 -328.

2. van den Berg MP, van Gelder IC, van Veldhuisen DJ. Depletion of atrial natriuretic peptide during longstanding atrial fibrillation. Europace 2004; 6: 433-437.

3. McKie PM, Burnett JC Jr. B-type natriuretic peptide as a biomarker beyond heart failure: Speculations and opportunities. Mayo Clin Proc 2005; 80: 1029-1036.

4. Roy D, Paillard F, Cassidy D, Bourassa MG, Gutkowska J, Genest J, et al. Atrial natriuretic factor during atrial fibrillation and supraventricular tachycardia. J Am Coll Cardiol 1987; 9: 509-514.

5. Inoue S, Murakami Y, Sano K, Katoh H, Shimada T. Atrium as a source of brain natriuretic polypeptide in patients with atrial fibrillation. J Card Fail 2000; 6: 92-96.

6. Lee SH, Jung JH, Choi SH, Lee N, Park WJ, Oh DJ, et al. Determinants of brain natriuretic peptide levels in patients with lone atrial fibrillation. Circ J 2006; 70: 100-104.

7. Wozakowska-Kaplon B, Opolski G. Atrial natriuretic peptide level after cardioversion of chronic atrial fibrillation. Int J Cardiol 2002; 83: $159-165$.

8. Silvet H, Young-Xu Y, Walleigh D, Ravid S. Brain natriuretic peptide is elevated in outpatients with atrial fibrillation. Am J Cardiol 2003; 92: $1124-1127$

9. Wozakowska-Kaplon B. Effect of sinus rhythm restoration on plasma brain natriuretic peptide in patients with atrial fibrillation. Am J Cardiol 2004; 93: 1555-1558

10. Thomas MD, Kalra PR, Jones A, Struthers AD, More RS. Time course for recovery of atrial mechanical and endocrine function post DC cardioversion for persistent atrial fibrillation. Int J Cardiol 2005; 102: $487-491$

11. Oral H, Scharf C, Chugh A, Hall B, Cheung P, Good E, et al. Catheter ablation for paroxysmal atrial fibrillation: Segmental pulmonary vein ostial ablation versus left atrial ablation. Circulation 2003; 108: $2355-2360$.

12. Kumagai K, Ogawa M, Noguchi H, Nakashima H, Zhang B, Miura $\mathrm{S}$, et al. Comparison of 2 mapping strategies for pulmonary vein iso- 
lation. Circ J 2005; 69: 1496-1502.

13. Tada H, Naito S, Kurosaki K, Ueda M, Ito S, Shinbo G, et al. Segmental pulmonary vein isolation for paroxysmal atrial fibrillation improves quality of life and clinical outcomes. Circ J 2003; 67: 861 865.

14. Tada H, Kurosaki K, Ito S, Naito S, Yamada M, Miyaji K, et al. Left atrial and pulmonary vein ostial ablation as a new treatment for curing persistent atrial fibrillation. Circ J 2005; 69: 1057-1063.

15. Teichholz LE, Kreulen T, Herman MV, Gorlin R. Problems in echocardiographic volume determinations: Echocardiographic-angiographic correlations in the presence of absence of asynergy. Am $J$ Cardiol 1976; 37: 7-11.

16. Tsuji T, Imagawa K, Masuda H, Haraikawa M, Shibata K, Kono M, et al. Stabilization of human natriuretic peptide in blood samples. Clin Chem 1994; 40: 672-673.

17. Tsutamoto T, Wada A, Maeda K, Hisanaga T, Maeda Y, Fukai D, et al. Attenuation of compensation of endogenous cardiac natriuretic peptide system in chronic heart failure: Prognostic role of plasma brain natriuretic peptide concentration in patients with chronic symptomatic left ventricular dysfunction. Circulation 1997; 96: 509-516

18. Wang TJ, Larson MG, Levy D, Benjamin EJ, Leip EP, Omland T, et al. Plasma natriuretic peptide levels and the risk of cardiovascular events and death. N Engl J Med 2004; 350: 655-663.

19. Berglund H, Boukter S, Theodorsson E, Vallin H, Edhag O. Raised plasma concentrations of atrial natriuretic peptide are independent of left atrial dimensions in patients with chronic atrial fibrillation. $\mathrm{Br}$
Heart J 1990; 64: 9-13.

20. Redfield MM, Rodeheffer RJ, Jacobsen SJ, Mahoney DW, Bailey KR, Burnett JC Jr. Plasma brain natriuretic peptide concentration: Impact of age and gender. J Am Coll Cardiol 2002; 40: 976-982.

21. Watanabe M, Murakami M, Furukawa H, Nakahara H, Tanaka H, Sunamori M. Decreased plasma brain natriuretic peptide levels after a successful maze procedure. J Heart Valve Dis 2003; 12: 287-291.

22. Wazni OM, Martin DO, Marrouche NF, Latif AA, Ziada K, Shaaraoui $\mathrm{M}$, et al. Plasma B-type natriuretic peptide levels predict postoperative atrial fibrillation in patients undergoing cardiac surgery. Circulation 2004; 110: 124-127.

23. Mabuchi N, Tsutamoto T, Maeda K, Kinoshita M. Plasma cardiac natriuretic peptides as biochemical markers of recurrence of atrial fibrillation in patients with mild congestive heart failure. Jpn Circ J 2000; 64: 765-771.

24. Conen D, Pfisterer M, Martina B. Substantial intraindividual variability of BNP concentrations in patients with hypertension. J Hum Hypertens 2006; 20: 387-391.

25. Hindricks G, Piorkowski C, Tanner H, Kobza R, Gerds-Li JH, Carbucicchio C, et al. Perception of atrial fibrillation before and after radiofrequency catheter ablation: Relevance of asymptomatic arrhythmia recurrence. Circulation 2005; 112: 307-313.

26. Lubien E, DeMaria A, Krishnaswamy P, Clopton P, Koon J, Kazanegra R, et al. Utility of B-natriuretic peptide in detecting diastolic dysfunction: Comparison with Doppler velocity recordings. Circulation 2002; 105: 595-601. 